\title{
Analysing interactions among the sustainable development goals: findings and emerging issues from local and global studies
}

\author{
Joseph Alcamo ${ }^{1,7}$. John Thompson ${ }^{2,7} \cdot$ Anthony Alexander $^{3,7} \cdot$ Andreas Antoniades $^{1,7} \cdot$ Izabela Delabre $^{3,7}$. \\ Jonathan Dolley $^{4,7}$. Fiona Marshall ${ }^{4,7} \cdot$ Mary Menton $^{5,7}$. Jo Middleton ${ }^{5,6,7}$. Jörn P. W. Scharlemann ${ }^{5,7}$
}

Received: 10 September 2020 / Accepted: 10 October 2020 / Published online: 28 October 2020

○) Springer Japan KK, part of Springer Nature 2020

\begin{abstract}
The topic of SDG interactions is a relatively new research area with many knowledge gaps. Some of these gaps are addressed in this summary of a Special Feature of Sustainability Science, including new findings and emerging issues on (1) the characteristics of SDG interactions; (2) methods/methodology to analyse these interactions; and (3) the elaboration of drivers that influence SDG synergies. The importance of scale is clear in two emerging issues. First, there is evidence of a disconnect between national planning for SDGs and their implementation at the local scale which is leading to SDG trade-offs between these scales. Second, the concept of a "critical transition zone" is introduced where SDG trade-offs pose a particular challenge to SDG implementation. These are areas (e.g., peri-urban and forest margin areas in the Global South) undergoing rapid biophysical and/or socio-economic changes and inhabited by populations especially vulnerable to these changes. While trade-offs occur among the SDGs, there are also many examples of synergies which provide opportunities for advancing multiple goals. To distinguish between synergies and the actions that exploit them, the term "synergy driver" is introduced to refer to policies and measures that positively advance two or more goals. Several examples of synergy drivers are presented, including sustainable global supply chains, people-centred early warning systems, and joint conservation-public health programmes. To make synergy drivers relevant to the broader policy community, the research community (working with stakeholders) should first consolidate knowledge about these drivers and then evaluate their effectiveness/applicability to different policy settings.
\end{abstract}

Handled by Osamu Saito, Institute for Global Environmental Strategies, Japan.

Joseph Alcamo

joseph.alcamo@sussex.ac.uk

1 School of Global Studies, University of Sussex, Brighton BN1 9SJ, UK

2 Institute for Development Studies, Brighton BN1 9RE, UK

3 University of Sussex Business School, University of Sussex, Brighton BN1 9SL, UK

4 Science Policy Research Unit, University of Sussex Business School, Brighton BN1 9SN, UK

5 School of Life Sciences, University of Sussex, Brighton BN1 9QG, UK

6 Dept. of Primary Care and Pub. Health, NIHR Global Health Research Unit on Neglected Trop. Diseases, Brighton and Sussex Medical School, Brighton BN1 9PX, UK

7 Sussex Sustainability Research Programme, University of Sussex, Brighton BN1 9QQ, UK

\section{Introduction}

The Sustainable Development Goals (SDG) are a universal call to action to end poverty, protect the planet and improve the lives and prospects of everyone, everywhere. Adopted by all UN Member States in 2015 as part of the 2030 Agenda for Sustainable Development, the 17 Goals form a framework for national action and global cooperation for transformative change (UN 2015). Because the goals were endorsed by every country in the world and have broad coverage, they have the potential to serve as a road map for 'building back better' after the Covid-19 pandemic (OECD 2020).

With just under 10 years left to achieve the SDGs, the UN recently declared a "Decade of Action" (2021-30) and pledged to mobilise financing, enhance national implementation and strengthen institutions to achieve the goals by the target date of 2030, leaving no one behind (UN 2019). 
The preamble to the goals declares that they are "integrated and indivisible", but in practice their implementation has focused almost entirely on single goals. For example, the UN's inventory of multi-stakeholder partnerships to support the SDGs shows that a vast majority of all partnerships focus on individual goals (UN 2020a). On the one hand, this "individual goal" approach is understandable since interest groups, government agencies and communities cluster around the topics represented by specific goals, such as water, food, health, or poverty alleviation. On the other hand, this approach neglects opportunities for transformative actions and multi-stakeholder collaborations that would advance more than one goal at the same time. Evidence is accumulating, some presented later in this paper, that some policies and measures advance multiple goals. Indeed, an alternative way of implementing the SDGs would be to take an "integrative approach" which would minimise "trade-offs" and promote "synergies" among the goals. Support for an integrative approach to the SDGs has been expressed in many political declarations (UN 2019, 2020b), academic papers (Sachs et al. 2019; Le Blanc 2015), and is promoted by an OECD-initiated partnership for "Policy Coherence for Sustainable Development" (OECD 2019). In particular, as national income decreases as an outcome of the COVID-19 crisis, an integrative approach to the SDGs has the potential to be a cost-effective way for countries to advance many SDGs simultaneously.

Although there is a growing body of literature around the concepts of SDG interactions and an integrative approach to the SDGs (e.g., Breuer et al. 2019; Kroll et al. 2019; Scharlemann et al. 2020) the study of SDG interactions is still a relatively new area of research with many knowledge gaps. The objective of this Special Feature of Sustainability Science is to reduce this gap by providing findings and emerging issues about three key topics: (1) characteristics of SDG interactions; (2) methods/methodology to detect and analyse SDG interactions; and (3) the elaboration of drivers that influence SDG synergies. Six of the ten papers in this Special Feature have a place-based perspective and provide empirical evidence from case studies in several countries in the Global South, plus the United Kingdom. Four of the papers have a global/international perspective.

The common focus of these papers is on interactions among the SDGs, in particular trade-offs and synergies. A "trade-off" is defined here as a condition by which an action to achieve one goal or target makes it more difficult to achieve one or more other goals or underlying targets; a "synergy" is a condition by which an action to achieve one goal helps achieve one or more other goals or targets.

\section{Characteristics of SDG interactions}

\section{Critical transition zones for SDG interactions}

A main assertion coming from studies of SDGs is that they are "context specific", i.e.. to achieve the goals it is advisable to take into account the social, political and environmental circumstances at particular locations (Oliveira et al. 2019; Weitz et al. 2018). This raises the question, are there specific types of locales where SDG interactions are particularly important for their implementation? Research in this Special Feature provides two possible examples of such locales, peri-urban areas and forest margins.

The areas surrounding cities, "peri-urban areas", contain about one-third of the world's cropland (assuming a $10 \mathrm{~km}$ buffer around cities; Nicholls et al. 2020) and are, therefore, very relevant to SDG 2 (end hunger). These areas are also undergoing rapid biophysical and/or socio-economic changes because of the continuing rapid expansion of cities, especially in Africa and Asia (UN DESA 2018). This threatens not only agricultural land and other ecosystem services in these areas (Marshall et al. 2018; Dolley et al. 2020) but also their large vulnerable populations. These include, for example, migrant farmers in Wuhan's peri-urban region (Dolley et al. 2020). The pressure of urbanisation and the mixture of rapid physical change and vulnerable populations leads to important trade-offs among the SDGs, especially among those related to food production (SDG 2), urban development (SDG 11), poverty alleviation (SDG1) and protecting terrestrial ecosystems (SDG 15). Marshall (2016) also classifies peri-urban areas as "sustainability frontiers" because they are "hot spots of social learning and innovation, as well as frontiers of transition and social transformation" with considerable potential to realise synergies between apparently conflicting urban development priorities (Marshall and Dolley 2019).

Many tropical forest margin areas are also undergoing rapid change which is eroding social-ecological resilience at the local and global levels, and threatening the livelihoods and culture of local and indigenous inhabitants of these areas (Rodrigues et al. 2009; Rasmussen et al. 2017). In the year spanning 2018-19, development destroyed in excess of $9700 \mathrm{~km}^{2}$ of the rainforest in the Brazilian Amazon, an increase of $30 \%$ over the previous year (Escobar 2019). Delabre et al. (2019) describe injustices that arise in Brazil from differing interpretations of 'sustainability' by various multi-stakeholder initiatives. Menton et al. (2020) describe the conflicts and environmental injustices that often arise in these regions due to expansion of extractive industries and large-scale agriculture (see also below). In sum, these studies articulate trade-offs occurring between 
economic growth (SDG 8), forest conservation (SDG 15), and the rights of local communities and indigenous peoples living in these areas (SDGs 3 and 10).

We propose that peri-urban and forest margin areas are members of a class of locations particularly relevant to SDG implementation which we call "critical transition zones". We define such a zone as a category of land (continental, coastal or island) on which biophysical and/or socio-economic changes are rapid relative to surrounding areas, and which have inhabitants particularly vulnerable to social or environmental impacts associated with the changes. This concept could also be expanded to cover non-settled areas where ecosystems are undergoing rapid change and at particular risk. Critical transition zones could, therefore, include not only sensitive terrestrial areas, but also aquatic and cryosphere settings.

We propose that these locations in the Global South merit special attention in the policy arena because of the intersection of rapid change and vulnerable populations (e.g., farm migrants in peri-urban areas, indigenous peoples in forest margins) coupled with degradation or loss of natural environments which creates barriers to achieving the SDGs. Trade-offs in these areas will have a particular impact on vulnerable social groups.

To further develop the concept of critical transition zones, the research community should work with stakeholders to develop criteria for these areas, and then use these criteria to compile an inventory of these zones. These data should then be conveyed to the policy arena.

Criteria are needed for the two aspects of critical transition zones-"rapid rates of change" and "vulnerable people". Possible criteria for "rapid rates of change" could be critically high rates of land use change, number of vulnerable people displaced, or number of vulnerable people losing livelihoods. All of these would be defined per unit area and time. The question arises, for a particular location, which of these metrics is most suitable, and what is "critically high"? A simple criterion for "vulnerable population" could be income level, but this neglects other important, locale-specific factors identified in the literature such as gender, age, livelihood situation, power relations, and type of threat (e.g., Thomas et al. 2019; Akmam et al. 2020). A preliminary conclusion is that criteria for both "rapid rates of change" and "vulnerable people" are best selected by considering local and national contexts and by working with stakeholders.

\section{Closing the gap between national SDG planning and local implementation}

Although responsibility for implementing the SDGs lies with national governments, the implementation itself takes place in local communities, businesses, and schools throughout each country. Of concern, recent research has provided examples of a gap between national planning for SDGs and local implementation of the goals.

- In Tanzania, there is evidence that national policies to boost food production through commercialisation of agriculture are resulting in the development of arable land by commercial operators at the expense of most local smallholder farmers (Newell et al. 2019). Although smallholders produce a third of the world's food supply and disproportionately more in sub-Saharan Africa (Ricciardi et al. 2018), they are still underrepresented in national planning. In terms of the global goals, this leads to tensions and trade-offs between the national planning for SDG 2 (end hunger) and local realisation of SDG 8 (decent work) and SDG 10 (reduced inequalities). An important dynamic here are the power relationships between different social groups (Newell et al. 2019).

- There is evidence from Kenya that local groups most affected by national plans for introducing "climate-smart agriculture" (smallholder farmers, fisher communities, pastoralists) (SDGs 2 and 13) are not engaged in national decision-making processes about how to implement this type of agriculture in their communities (Newell et al. 2018).

- In Ecuador, research has shown that national policies to advance economic growth (SDG 8) via increased oil extraction have caused environmental degradation and health impacts near extraction sites that harm poor and indigenous people. Furthermore, oil extraction has not markedly improved their economic condition (Menton et al. 2020; Larrea et al. 2020). As a result, striving to achieve SDG 8 (economic growth) at the national and international levels is making it more difficult to achieve SDG 3 (good health) and SDG 15 (life on land) at the local level, sometimes leading to violence (see below).

These are not isolated examples but symptomatic of a widespread disconnect between national SDG planning and its local implementation. For example, as of 2019 , only $42 \%$ of national governments gave local or regional governments an active role in preparing the voluntary national reviews of the SDGs (Lieberman 2019).

On the positive side, there are cases in which national governments have worked successfully with local stakeholders to help implement the goals. For instance, the Australian government in the context of the SDGs has supported a major greening programme in the city of Melbourne, as well as school nutrition projects in the Northern Territory aimed at "improving school attendance and local Aboriginal and Torres Strait Islander employment through the provision of healthy meals to students on school days" (Australian government 2018). Meanwhile, the German Federal Ministry for Economic Cooperation and Development has provided 
support to the city of Bonn for developing a municipal sustainability strategy to "localise" the SDGs. This strategy will help the city provide affordable housing, develop sustainable transport, and maintain its green areas (OECD 2020). More examples of "vertical coordination to align local, regional, national and global priorities" are given in OECD (2020).

Further case studies and surveys would help clarify the extent of national-local disconnects, and conversely, the progress being made to coordinate national SDG planning with local SDG implementation.

The more serious examples of national-local disconnects can lead to environmental and social injustice. Dolley et al. (2020) found trade-offs between the benefits of urbanisation to a wider population and the negative impacts of displacement on migrant farmers in peri-urban areas in Wuhan, China (see below). As Orchard et al. (2019) highlight, efforts to increase income and food production through agricultural intensification (SDG 1 and 2) can lead to loss of socio-ecological resilience in households.

In some cases, support for extractive industries and large-scale agriculture (SDGs 2 and 8 ) is linked to violence against local communities and indigenous peoples, including murders of environmental and land defenders and other physical and structural violence (Menton et al. 2020). Butt et al. (2019) found that killings of environmental defenders were highest in countries with weak rule-of-law and high levels of corruption. In a global study of 2743 cases of environmental conflicts, Scheidel et al. (2020) found high rates of criminalisation of activists (20\%) and physical violence against them (18\%).

The prevalence of environmental, land and resource conflicts, and the consequent social and environmental injustices and violence experienced by marginalised and vulnerable communities highlights the importance of rights-based approaches to the SDGs and the role of governance (SDG16) in mitigating these injustices (Menton et al. 2020).

\section{Different entry points, different methods to explore SDG interactions}

To be relevant to the national policy arena and implementation of the SDGs, researchers must be able to identify and prioritise SDG interactions. Yet this is a non-trivial task since there are over 10,000 pairwise combinations of the 169 SDG targets, with a much larger number if three-way or higher level interactions are included. ${ }^{1}$

\footnotetext{
1 The general formula for computing the number of combinations in a set without repetition is $C(n, r)=\frac{n !}{k !(n-k) !}$ where $n$ is the set size, and $k$ the sample set. The "!" symbol denotes a factorial. To calculate the total number of unique pairwise combinations in the entire set of SDG targets, $n=$ number of targets $=169$ and $k=2$ for pairwise com-
}

Several frameworks have been developed to identify and prioritise SDG interactions, but the research community has not converged upon a single method or methodology. Each approach has its advantages and limitations, and there is an ongoing need for methodological development. The SDG Conceptual Network Diagrams developed at the UN Department of Economic and Social Affairs (Le Blanc 2015) is useful for identifying targets that are central nodes in a network of SDGs, but the framework is qualitative and does not provide the means to quantify or interrogate the importance or nature of the trade-offs and synergies. The Framework for Understanding SDG Interactions created by the International Science Council (ICSU 2017) provides insight into the intensity and direction of relationships between SDGs but is reliant upon expert judgement. The SDG Interlinkages Analysis and Visualisation Tool devised by the Institute for Global Environmental Strategies (IGES) (Zhou et al. 2017,2019 ) is quantitative in nature, and visually maps and assigns strengths to linkages between SDGs. However, the IGES tool does not simulate specific policies over the SDG time horizon and, therefore, cannot be used to assess synergies associated with different policy mixes. A review of methods is given by Scharlemann et al. (2020) and Breuer et al. (2019).

One way to simplify the task of identifying and prioritising interactions is to select a specific "entry point" to the interactions and to focus on connections specific to this entry point. For example, Alcamo (2019) uses water quality as an entry point to SDG interactions and identified the interlinkages of the SDG water quality target with other SDG targets. This approach limits the number of interactions to a manageable number and provides substantive information about where joint actions could achieve multiple SDGs. However, the "single entry point" approach may not provide the data needed in a particular policy setting. For example, it will not indicate the most important interactions among the entire set of SDGs.

The body of research presented in this Special Feature highlights numerous entry points, and here we present three examples: (1) human-environment interactions; (2) poverty alleviation; and (3) peri-urban agriculture. For each of these, the authors use a different method for analysing SDG interactions, with new methodological elements. In the first example, Scharlemann et al. (2020) apply an "influence matrix" in a unique fashion to identify the importance of SDG interactions through the lens of human-environment interlinkages. In the second, Antoniades et al. (2019) present a new application of econometrics to identify the

Footnote 1 (continued)

binations of targets. Therefore $C(n, r)=14,196$. For combinations of three targets, $k=3$ and $C(n, r)=790,244$. 
relationships between the SDG on poverty alleviation with other SDGs. In the last example, Dolley et al. (2020) present a new web-based GIS tool to examine spatial aspects of SDG trade-offs.

\section{Environment-human interlinkages as entry point and influence matrix as method}

Several authors have used an "influence matrix" or conceptually similar methods to identify priority SDGs interactions. For example, matrices have been used to investigate SDG interactions for different geographic areas (e.g., Allen et al. 2019) and subsets of goals (e.g., Weitz et al. 2018).

In this Special Feature, Scharlemann et al. (2020) use an influence matrix to examine pairwise interactions among 16 goals (excluding the "enabling" SDG 17). They investigate two aspects of SDG interactions: (1) The degree to which an action to achieve one goal (e.g., research, innovation, policy, management) influences the achievement of other goals; and (2) How deliberately taking a particular perspective (geographic, political, temporal, sectoral or social group) influences SDG interactions (interdependencies, co-benefits and trade-offs). For their particular application, they use "environment-human interlinkages" as an entry point and show that the environment is integral to almost all goals (words related to the environment are mentioned in 13 SDGs and in 62 out of 150 SDG targets). They also identify 20 pairwise goal interactions where environment-human interlinkages may be most influential.

This approach provides a useful tool to guide decisionmaking in practice because it focusses on actions and allows consideration of different sectoral perspectives. Comparing influence matrix assessments on SDG interactions conducted from multiple perspectives will explicitly highlight the potential influences of a decision made in one sector on other sectors, encouraging cooperation across sectors to achieve multiple goals.

\section{Poverty alleviation as entry point and econometrics as method}

Human-environment interlinkages, as discussed above, are only one of the many entry points for investigating SDG interactions. Another important entry point is poverty alleviation, declared by Signatories of the SDGs (UN 2015) as "the greatest global challenge". Using this as an entry point, Antoniades et al. (2019) estimate the impact of financial distress on multidimensional poverty dynamics in the context of SDG implementation, which provides new information about the interlinkages between SDG 1 (no poverty) and other SDGs.

Their approach was to use econometrics to investigate how more than 400 international financial crises since 1980 have simultaneously affected SDG indicators for poverty and related variables. Antoniades et al. found that episodes of financial distress, as currently experienced in many Global South countries, are associated with an increase in the poverty headcount and the poverty gap, a decrease in access to basic sanitation (SDG 6), a decrease in access to electricity (SDG 7), an increase in maternal mortality (SDG 3), an increase in particulate pollution (SDGs 3 and 11), a higher number of children out of school, and a decrease in education expenditure (SDG 4). In addition, they are associated with an increase in $\mathrm{CO}_{2}$ from forest removals and forest rents (SDG 13), and a decrease in terrestrial land protection (SDG 15). The impact is stronger on low-income countries and there are particularly strong negative feedback loops between income poverty and education. Financial crises had a deleterious effect on both government policies (a 27.5\% average reduction of global education expenditures) and directly on households (children out of school at primary school age). This is of critical relevance to attaining the SDGs since a lack of education locks countries and individuals into a vicious cycle of poverty.

With regard to solutions, Antoniades et al. note that the high level of debt of some low-income countries is a barrier to meeting SDG targets. The authors note that if wealthier countries were to "assist developing countries in attaining long-term debt sustainability through coordinated policies", as called for in SDG target 17.4, poor countries would have substantially greater resources to invest in poverty alleviation.

\section{Peri-urban food production as entry point and spatial analysis as method}

In contrast to the preceding examples, Dolley et al. (2020) present a method to evaluate SDG interactions that is spatially explicit. With an example from Wuhan, China (see below), they show that spatial analysis has the potential to provide unique data for analysing SDG trade-offs and synergies.

Intensive vegetable production in the peri-urban areas of Wuhan provide a significant fraction of the fresh produce consumed by the city's population and essential livelihoods to the migrant farmers who make up a large proportion of farmers in this area. But land here is being developed for infrastructure and industrial activity and a higher level of economic activity at the expense of vegetable farming and its benefits. To correctly assess the scale of these trade-offs it is necessary to take into account the spatial location of new infrastructure and industrial development relative to population, farming areas, and sensitive natural areas, i.e., to carry out a spatial analysis. To accomplish this task, Dolley et al. (2020) developed a new interactive web-based GIS tool with the aim to visualise trade-offs related to SDGs that play out 
Table 1 Characteristics of three methods presented in the Special Feature to identify and prioritise SDG interactions

\begin{tabular}{|c|c|c|c|c|c|c|}
\hline Method & $\begin{array}{l}\text { Level of external } \\
\text { data requirements }\end{array}$ & $\begin{array}{l}\text { Level of expert } \\
\text { judgement }\end{array}$ & Interactive? & $\begin{array}{l}\text { Spatially explicit } \\
\text { results? }\end{array}$ & $\begin{array}{l}\text { Application pre- } \\
\text { sented in Special } \\
\text { Feature }\end{array}$ & $\begin{array}{l}\text { Reference from } \\
\text { Special Feature }\end{array}$ \\
\hline Influence matrix & Low & High & Yes & $\begin{array}{l}\text { No, but can be } \\
\text { applied at various } \\
\text { spatial scales, } \\
\text { village-country- } \\
\text { global }\end{array}$ & $\begin{array}{l}\text { Identifying oppor- } \\
\text { tunities for linking } \\
\text { environmental } \\
\text { policies and } \\
\text { measures with } \\
\text { other sectors for } \\
\text { advancing multiple } \\
\text { SDGs }\end{array}$ & $\begin{array}{l}\text { Scharlemann et al. } \\
\text { (2020) }\end{array}$ \\
\hline Econometrics & Medium & Low-medium & No & No & $\begin{array}{l}\text { Estimating how } \\
\text { changing eco- } \\
\text { nomic conditions } \\
\text { affect interactions } \\
\text { between the pov- } \\
\text { erty goal and other } \\
\text { SDGs }\end{array}$ & $\begin{array}{l}\text { Antoniades et al. } \\
\text { (2019) }\end{array}$ \\
\hline Web-based GIS tool & High & Medium & Yes & Yes & $\begin{array}{l}\text { Investigating } \\
\text { impacts of land } \\
\text { use changes on } \\
\text { SDG interactions }\end{array}$ & Dolley et al. (2020) \\
\hline
\end{tabular}

spatially for different land use changes in a peri-urban setting. Their approach combines high-resolution, top-down remote sensing data with bottom-up knowledge and diverse stakeholder perspectives. Making the tool web-based gives stakeholders an opportunity to use it interactively, e.g., to customise land use classes or to specify the value of different land use changes (see below).

Dolley et al. (2020) tested and applied the tool to a periurban district of Wuhan, using it to assess the loss of vegetable farms and other land uses resulting from new infrastructure and industrial development. They demonstrated how users (e.g., stakeholders) of the tool can assign positive or negative values to different changes in land use. This allows users to quantify the trade-offs that occur between gains in economic activity (SDG target 8.2) and losses of specific vegetable growing areas, reduced food production, threatened food safety (SDG target 2.1) and displacement of farmers and their livelihoods (SDG target 10.7). In sum, this spatial approach provides both visual and quantitative data for assessing SDG interactions in a policy setting and can incorporate stakeholder views.

\section{Comparing methods}

In comparing the method of Dolley et al. (2020) with the two methods described earlier (Table 1), the web-based GIS tool probably has the largest external data requirements. Although the econometrics approach used by Antoniades et al. (2019) also requires a substantial amount of time series data, it does not need the spatial resolution of data used by the GIS tool (therefore, the external data requirements of the econometrics approach are set at "medium" in Table 1). The SDG influence matrix, as applied by Scharlemann et al. (2020), uses expert judgement for ranking the importance of SDG interactions whereas the other methods use statistical methods. All three methods use expert judgement to decide on which variables are to be included in the analyses.

Both the influence matrix and web-based GIS tool are partly interactive. With the influence matrix, experts can specify values and apply various perspectives. With the webbased GIS tool, stakeholders can intervene in ways described above. In the econometrics approach, once the data to be used are specified, it cannot be said to be "interactive" in the same way.

As noted above, the web-based GIS tool produces spatial data which have certain advantages in SDG trade-off analysis. The other methods do not produce spatially explicit results, although influence matrices can be prepared, and compared, at multiple spatial (and temporal) scales from local to national to global.

With their unique characteristics, the three methods have been applied to different issues associated with SDG interactions (Table 1) and are likely to have potential applications in other settings. Also, these methods are not mutually exclusive, but it is expected that they can be used in combination or with other methods to investigate SDG synergies and trade-offs. For example, constructing an influence matrix can help identify the GIS layers to be included in a spatial analysis. 
Table 2 Examples of "synergy drivers" from the Special Feature

\begin{tabular}{|c|c|c|}
\hline Synergy driver & $\begin{array}{l}\text { Reference from Special Feature or associated litera- } \\
\text { ture explaining synergy driver in context of SDG } \\
\text { interactions }\end{array}$ & $\begin{array}{l}\text { SDGs positively influenced } \\
\text { by synergy driver. See text for } \\
\text { explanation }\end{array}$ \\
\hline $\begin{array}{l}\text { Sustainable agriculture applications to peri-urban } \\
\text { areas }\end{array}$ & $\begin{array}{l}\text { Marshall and Randhawa (2017); Marshall et al. } \\
\text { (2018); Nicholls et al. (2020) }\end{array}$ & SDGs $1,2,3,11,13,15$ \\
\hline $\begin{array}{l}\text { Sustainable nutrient management (an element of } \\
\text { sustainable agriculture) }\end{array}$ & Alcamo (2019) & SDGs $2,3,6,13,14$ \\
\hline Sustainable supply chain management & Alexander and Delabre (2019) & SDGs $8,12,13,14,15,16,17$ \\
\hline $\begin{array}{l}\text { Jurisdictional approach to integrated landscape } \\
\text { development }\end{array}$ & Delabre et al. (2019) & SDGs $2,15,16$ \\
\hline Integrated conservation and health programmes & Middleton et al. (2020) & SDGs $3,5,14,15$ \\
\hline Sustainability assessment reports in trade agreements & Amos and Lydgate (2019); Lydgate and Amos (2020) & SDG $6,8,13,14,15$ \\
\hline $\begin{array}{l}\text { People-centered early warning systems for agriculture } \\
\text { and fisheries }\end{array}$ & Martin and Osella (2019); Wilkinson et al. (2018) & SDGs $2,8,13$ \\
\hline
\end{tabular}

\section{Synergy drivers}

Here we briefly review results about synergies from the Special Feature and introduce the idea of synergy drivers as a vehicle for applying synergies in the policy arena.

Several authors have estimated that synergies occur more frequently than trade-offs among SDGs (Donoghue and Khan 2019; Langou et al. 2020; Weitz et al. 2018), and this is a promising result for an integrative approach to the SDGs. But there has been less research on how to actually exploit synergies in the policy sphere and how to advance multiple goals on a practical basis. There has also been a lack of clarity as to the difference between "synergies", which are relationships among goals, and actions that take advantage of these synergies. Typical approaches to studying SDG interactions, such as influence matrices and statistical analyses of historical indicators, are very valuable in identifying the state of relationships between SDGs, but do not necessarily provide information about the effectiveness of actions to exploit the goals.

To distinguish between "synergies" and the actions that exploit these synergies, the term "synergy driver" is introduced here. We define "synergy driver" as a policy or measure carried out locally, nationally, or internationally that helps achieve two or more SDGs at the same time by capitalising on the positive interconnections among the goals. (We use "policies and measures" in the sense, it is used by the UN and other international institutions. ${ }^{2}$ By advancing

\footnotetext{
2 "Policies ... refer to objectives, together with the means of implementation ... Measures can be individual interventions or they can consist of packages of related measures. Specific measures might include actions that promote the chosen policy direction, such as implementing an irrigation project ..." (UNDP 2004, p. 249).

"A policy is commonly understood as the overarching framework to achieve certain objectives, which sets the overarching frame for actions. A policy may include several measures. Examples are: Renewable Energy Strategy, Green Fund ... A measure is commonly
}

multiple goals at the same time, synergy drivers have the potential to save resources in achieving the SDGs by harmonising, coordinating, or combining efforts to achieve the different SDGs (Farhan and Niaz 2016; Alcamo et al. 2018).

Papers in the Special Feature, or from authors conducting research associated with it, contain several examples of synergy drivers (Table 2):

- In peri-urban areas in India and the UK, there is evidence that sustainable agricultural practices can promote not only the goal for ending hunger (SDG 2), but also goals for poverty (SDG 1), health (SDG 3), land biodiversity (SDG 15) and sustainable cities (SDG 11) (Marshall and Randhawa 2017; Marshall et al. 2018; Nicholls et al. 2020). Evidence from peri-urban areas as widely separated as Wuhan in China (Dolley et al. 2020) and Brighton in the UK (Nicholl et al. 2020) indicate that peri-urban farms, owing to their proximity to urban markets, provide a disproportionate amount of high-nutrition fresh fruits and vegetables to nearby city dwellers. In addition, sustainable agricultural practices in peri-urban areas contribute to climate resilience (SDG 13) by reducing physical exposure to floods and droughts; they also reduce climate change risks by increasing socio-economic resilience to hazard impacts and by often enhancing the amount of carbon dioxide sequestered in soils (Mngumi 2020).

- Sustainable nutrient management is a specific example of a sustainable agricultural practice and has a high poten-

\section{Footnote 2 (continued)}

understood as concrete actions undertaken to implement a certain policy. A measure is more concrete than a policy. Examples are introduction of a carbon tax, insulation of buildings..." (EEA 2019, pp. 55-56). 
tial for reducing the runoff of nitrogen from cropping and livestock areas which is causing local and coastal water pollution. In this way, it helps achieve targets for reducing freshwater pollution (SDG 6) and marine pollution (SDG 14). Moreover, it reduces nitrate levels in water supplies, helping to achieve health objectives (SDG 3 ). Sustainable nutrient management also frequently increases crop yields (SDG 2), and reduces emissions of the greenhouse gas nitrous oxide, helping to achieve the climate goal (SDG 13) (Alcamo 2019; UNEP 2013).

- Sustainable supply chain management is an approach to ensure transparency of international supply chain operations and support corporate social responsibility. It aims to honour the rights of local and indigenous communities, protect worker's rights and safety, and reduce or avoid the carbon footprint and other environmental impacts of the supply chain including deforestation. In forest margin areas of Brazil, Ecuador and elsewhere sustainable supply chain management has the potential to advance the SDGs for decent work (SDG 8), social justice (SDG 16), and land biodiversity (SDG 15), and enhance international partnerships (SDG 17) (Alexander and Delabre 2019). Furthermore, transforming the management of supply chains also contributes to better use of materials and resources (SDG 12) (Yagi and Kokubu 2020) provides climate benefits (SDG 13) (Campbell et al. 2018) and improves management of fisheries (SDG 14) (Zelasney et al. 2020).

- Jurisdictional approaches to landscape development have been applied in Brazil and elsewhere and are broadly defined as "...frameworks that seek to align governments, businesses, NGOs, and local stakeholders in specific administrative jurisdictions around common interests in land use governance" (Brandao et al. 2020). They are synergy drivers in the sense that they support sustainable agriculture (SDG 2), forest conservation (SDG 15) and help to "develop effective, accountable and transparent institutions at all levels", as well as other targets of SDG 16 (Delabre et al. 2019).

- In Papua New Guinea and elsewhere, integrated forest conservation and health programmes have been organised in low-income villages in deforestation zones. These projects have the potential to support both the health (SDG 3) and land biodiversity (SDG 15) goals, as well as improving access of women to reproductive and sexual health services (an SDG 5 gender equality target) (Middleton et al. 2020).

- In the UK and elsewhere, researchers have found that international trade agreements are leading to major trade-offs among the SDGs (Amos and Lydgate 2019). To counter these trade-offs, it has been proposed to embed Sustainability Assessments into existing and new trade agreements. This can be an effective policy tool for achieving greater compliance with the decent work and economic growth aspects of SDG 8, and help advance the goals for clean water (SDG 6), climate (SDG 13), marine protection (SDG 14), and biodiversity (SDG 15) (Amos and Lydgate 2019; Lydgate and Amos in preparation).

- In farming communities in Kenya and fisher communities in South India, research has found that "people-centered early warning systems" for extreme weather events (national early warning systems tuned to the needs of specific communities and locales) can help these communities adapt to extreme weather conditions related to climate variability (SDG 13), as well as protect their livelihoods (SDG 8). Consequently, these early warning systems also increase the food security of farmers and fishers and the communities they provide food for (SDG 2). (Martin and Osella 2019; Wilkinson et al. 2018).

This list of synergy drivers (Table 2) is significant because it shows that specific actions exist to advance multiple SDGs and that they arise in many different local settings and policy contexts around the world. This list also illustrates their diversity, showing that some drivers are policies (e.g., embedding sustainability assessments in new trade agreements) while others are socio-technical measures (e.g., sustainable agriculture). Some synergy drivers are a combination of the two (e.g., integrated conservation and health programmes). Some have a local focus (e.g., people-centred early warning systems) whereas others have a national or global focus (e.g., sustainable supply chain management). Clearly, to make synergy drivers relevant to the broader policy community two major tasks are necessary:

First, knowledge about synergy drivers should be consolidated. This includes compiling and categorising these drivers and building up a publicly available evidence base of their performance. For example, in this issue, Middleton et al. (2020) note the inadequacy of the published evidence base to support the scaling up of integrated conservation and health programmes.

Second, the effectiveness of synergy drivers must be evaluated. This has two aspects-evaluating their applicability to specific geographic and sectoral settings; and assessing the degree to which they can be scaled up and applied to many different settings.

The evaluation of synergy drivers should address the following issues:

- Applicability to location. To which location and circumstance is a particular synergy driver applicable? For some approaches, e.g., integrated forest conservation and health programmes, the target location (forests) is clear, but this is not the case for all synergy drivers. 
- Added value of integrated vs. individual goal approach. How effective is a synergy driver in advancing several SDGs as compared to advancing the goals individually? For example, to what degree can sustainable agricultural practices in peri-urban areas contribute to the national or local implementation of goals for food production, conservation of biodiversity, and livelihoods of vulnerable farmers as opposed to alternative actions to address these goals individually?

- SDG priorities. Which synergy driver is relevant to local-national SDG priorities? These priorities are likely to vary substantially between locales and countries. For example, a survey of 34 African countries indicated agreement among most countries on the first priority (SDG 8, decent work and economic growth), but wide disagreement on second and third priorities (Coulibaly et al. 2018)

- Costs vs. benefits. What are the costs vs. benefits of implementing the synergy driver? In deciding on a particular policy or measure, decision-makers usually assess costs and benefits, either formally or informally. Costs could include conventional costs of labour and materials to implement a policy or measure. For benefits, one criterion could be the extent to which a synergy driver improves the wellbeing of the most vulnerable social groups, in accordance with "Leaving no one behind". Another could be the number of people, or area of land or marine area, or area of sensitive ecosystem, positively affected by the synergy driver.

- Metrics for evaluation. What metrics should be used for assessing synergy drivers? One option is to use the official set of indicators used by countries to track their progress in reaching the SDGs (IAEG-SDGs, 2020). In an example mentioned earlier, Antoniades et al. (2019) used several SDG indicators including poverty headcount, access to safe drinking water, and terrestrial protected areas, in their analysis of SDG interactions.

Finally, considering that 2030, the target year for SDGs, is fast approaching and that it usually takes several years to translate research results into policy action, it is urgent to address the preceding questions as quickly as possible.

To accelerate this process, these questions could be addressed at expert-stakeholder workshops organised by academia, national governments, the UN or as a collaboration between these and other actors. Because synergy drivers encompass so many different disciplines, these workshops should be organised in an interdisciplinary fashion. (But, the organisers of these workshops should also anticipate and plan for the unavoidable difficulties of running such an interdisciplinary activity; Cairns et al. 2020.) Ultimately, the workshops could also be vehicles for conveying results quickly to policy fora.

\section{Concluding remarks}

While there is political support for an integrative approach to the SDGs and a growing body of literature on the goals, many gaps remain in our understanding of the interactions among the SDGs and how these may cause trade-offs or foster synergies. This Special Feature helps fill in a few of these important knowledge gaps.

Carrying out multiple place-based case studies in several countries in Latin America, Africa, and Asia (as well as the UK) has provided data for comparing findings from diverse settings. It has yielded insights that could have been overlooked in a national study or single case study.

For example, we have identified two emerging issues that have an important place-based aspect. First, evidence from case studies in Latin America and Africa indicates a disconnect at some locations between national planning for SDGs and their implementation at the local scale which is leading to SDG trade-offs between these scales. Second, case studies in Latin America and Asia have suggested the occurrence of "critical transition zones" that pose particular challenges to SDG implementation. Peri-urban and forest margin areas in the Global South are proposed as two examples of these zones.

Both issues merit attention from policymakers and stakeholders. An inventory of critical transition zones might provide useful input to the setting of priority areas for SDG implementation. Meanwhile, the disconnect between national planning and local implementation can be addressed by engaging local stakeholders more directly in national decision-making processes. We recognise, however, that this is a complex process that requires careful preparation and sensitivity to contending actors and interests.

There are also many gaps in methodologies to identify and prioritise SDG interactions. The three methods presented herein show the diversity of methods that can be useful in investigating SDG interactions. One of the three showed that spatial analysis of land use change has the potential to provide an entirely new perspective on tradeoffs and synergies among the SDGs.

Finally, the public health tragedy of the COVID-19 pandemic has also become a global socio-economic and environmental crisis with impacts on all 17 SDGs [Although levels of greenhouse gases and other pollutants have temporarily decreased during the pandemic, there is evidence that environmental pollution is returning to earlier or higher 
levels (Gardiner 2020). However, there are also many positive efforts underway to "build back better" which may lead to a greater emphasis on sustainability in public policy].

Since this crisis endangers progress towards the SDGs, a transformative recovery from COVID-19 is needed, and one that mitigates the current pandemic, reduces risks from future potential crises, and relaunches efforts to deliver the SDGs during the UN Decade of Action. Given this background, an integrative approach to the SDGs may have a special role to play in the recovery; by exploiting synergies among the SDG goals and targets, an integrative approach can help achieve multiple SDGs efficiently, and in so doing save resources.

It is a good time, therefore, to clarify and act on the concepts around SDG synergies. To distinguish between "synergies" and the actions that exploit them, we have introduced the term "synergy driver" to describe policies and measures that advance two or more goals. Countries will now ask, "Which synergy drivers save resources for implementing the SDGs? In which contexts and at what geographic levels will they work?" These and other related questions should be high on the agenda of researchers working on SDG interactions, and the community of policy-makers and practitioners seeking to make the most of this research.

\section{References}

\section{*Part of the Special Feature of Sustainability Science on "Exploring Interactions among the Sustainable Development Goals: Case Studies from Three Continents"}

Akmam W, Hasin SL, Islam MF (2020) Gender and age as actors in disaster vulnerability: a study of river erosion victims in Bogra District, Bangladesh. In: Madden J, Shibusawa H, Higano Y (eds) Environmental economics and computable general equilibrium analysis. New Frontiers in Regional Science: Asian Perspectives, vol. 41, Springer, Singapore. https://doi. org/10.1007/978-981-15-3970-1_19

Alcamo J (2019) Water quality and its interlinkages with the Sustainable Development Goals. Curr Opin Environ Sustain 36:126-140

Alcamo J, Grundy C, Scharlemann J (2018) Interactions among the Sustainable Development Goals, and why they are important. SSRP (Sussex Sustainability Research Programme), University of Sussex and Institute of Development Studies, Brighton, UK. Policy Brief 1. www.sussex.ac.uk/ssrp/sdg-interactions. Accessed 15 Aug 2020

Alexander A, Delabre I (2019) Linking sustainable supply chain management with the Sustainable Development Goals: indicators, scales and substantive impacts. In: Yakovleva N, Frei R, Rama Murthy S (eds) Sustainable development goals and sustainable supply chains in the post-global economy. Greening of industry networks studies, vol 7. Springer, Berlin
Allen C, Metternicht G, Wiedmann T (2019) Prioritising SDG targets: assessing baselines, gaps and interlinkages. Sustain Sci. 14:421438. https://doi.org/10.1007/s11625-018-0596-8

Amos R, Lydgate E (2019) Trade, transboundary impacts and the implementation of SDG 12. Sustain Sci. https://doi.org/10.1007/ s11625-019-00713-9

*Antoniades A, Widiarto I, Antonarakis AS (2019) Financial crises and the attainment of the SDGs: an adjusted multidimensional poverty approach. Sustain Sci. https://doi.org/10.1007/s1162 5-019-00771-z

Australian Government (2018) Department of Foreign Affairs and Trade, Report on the implementation of the Sustainable Development Goals (Voluntary National Review of SDG Progress). https://www.dfat.gov.au/sites/default/files/sdg-voluntary-natio nal-review.pdf. Accessed 15 Aug 2020

Brandão F, Piketty M-G, Poccard-Chapuis R et al (2020) Lessons for jurisdictional approaches from municipal-level initiatives to halt deforestation in the Brazilian Amazon. Front Forests Global Change 3:96. https://doi.org/10.3389/ffgc.2020.00096

Breuer A, Janetschek H, Malerba D (2019) translating sustainable development goal interdependencies into policy advice. Sustainability 11:20. https://doi.org/10.3390/su11072092

Butt N, Lambrick F, Menton M, Renwick A (2019) The supply chain of violence. Nat Sustain 2(8):742-747

*Cairns R, Hielscher S, Light A (2020) Collaboration, creativity, conflict and chaos: doing interdisciplinary sustainability research. Sustain Sci. https://doi.org/10.1007/s11625-02000784-Z

Campbell B, Hansen J, Rioux J, Stirling CM, Twomlow S, Wollenberg E (2018) Urgent action to combat climate change and its impacts (SDG 13): transforming agriculture and food systems. Curr Opin Environ Sustain 34:13-20

Coulibaly M, Ségorbah Silwé K, Logan C (2018) Taking stock: citizen priorities and assessments three years into the SDGs. Afro barometer Policy Paper No. 51. https://afrobarometer.org/sites/defau 1t/files/publications/Dispatches/ab_r7_policypaperno51_afric ans_priorities_the_sdgs_and_govt_performance.pdf. Accessed 15 Aug 2020

*Delabre I, Alexander A, Rodrigues C (2019) Strategies for tropical forest protection and sustainable supply chains: challenges and opportunities for alignment with the UN sustainable development goals. Sustain Sci. https://doi.org/10.1007/s11625-019-00747-z

*Dolley J, Marshall F, Butcher B et al (2020) Analysing trade-offs and synergies between SDGs for urban development, food security and poverty alleviation in rapidly changing peri-urban areas: a tool to support inclusive urban planning. Sustain Sci. https://doi. org/10.1007/s11625-020-00802-0

Donoghue D, Khan A (2019) Achieving the SDGs and 'leaving no one behind': maximising synergies and mitigating trade-offs. ODI Working Paper 560. Overseas Development Institute, London

EEA (European Environment Agency) (2019) Guidelines for reporting on policies and measures by member states under regulation (EU) No 525/2013 (EU Monitoring Mechanism Regulation), pp. 55-56. https://cdr.eionet.europa.eu/help/mmr/MMR\%20Art icle\%2013\%20Reporting\%20Manual\%20PaMs\%20(2018).pdf. Accessed 15 Aug 2020

Escobar H (2019) Brazil's deforestation is exploding-and 2020 will be worse. Science Magazine Nov. 22, 2019. https://www.scien cemag.org/news/2019/11/brazil-s-deforestation-exploding-and2020-will-be-worse. Accessed 15 Aug 2020

Farhan S, Niaz Z (2016) Avenues of alignment between Sustainable Development Goals and the Paris Agreement in India. Development Alternatives Issue Brief. https://www.devalt.org/Pdf/ L2_SixThemePdfs/Climate\%20SDG\%20Paper.pdf?Oid=115. Accessed 15 Aug 2020 
Gardiner B (2020) Why Covid-19 will end up harming the environment. National Geographic. https://www.nationalgeographic.com/ science/2020/06/why-covid-19-will-end-up-harming-the-envir onment/. Accessed 15 Aug 2020

IAEG-SDGs (Interagency and Expert Group on SDG Indicators) (2019) Tier classification for global SDG indicators. https://unsta ts.un.org/sdgs/iaeg-sdgs/tier-classification/. Updated 2020: https ://unstats.un.org/sdgs/iaeg-sdgs/2020-comprev/UNSC-proposal/. Accessed 15 Aug 2020

ICSU (2017) A guide to SDG interactions: from science to implementation. International Council for Science (ICSU), Paris

Kroll C, Warchold A, Pradham P (2019) Sustainable Development Goals (SDGs): are we successful in turning trade-offs into synergies? Palgrave Commun 5:140. https://doi.org/10.1057/s4159 9-019-0335-5. www.nature.com/palcomms. Accessed 15 Aug 2020

Langou GD, Florito J, Biondi A, Sachetti FC, Petrone L (2020) Leveraging synergies and tackling trade-offs among specific goals. Chapter 5 in Southern Voice (ed) Global state of the SDGs: three layers of critical action (Report 2019). Southern Voice, Santiago. pp. 93-144

Larrea C, Baroja C, Durango J, Menton M, Peck M, Sáenz M (2020) Oil extraction and local social development in the Ecuadorian Amazon. Working Paper. https://repositorio.uasb.edu.ec/handl e/10644/7080. Accessed 15 Aug 2020

Le Blanc D (2015) Towards integration at last? The sustainable development goals as a network of targets. Sustain Develop 23:176-187

Lieberman A (2019) UN forum reveals continued disconnect between SDGs and local work. Devex report. https://www.devex.com/ news/un-forum-reveals-continued-disconnect-between-sdgs-andlocal-work-95303. Accessed 15 Aug 2020

Lydgate E, Amos R. Trade and sustainability: assessing the sustainability impact of trade agreements. SSRP Policy Brief 4 (in preparation)

Marshall F (2016) Recognizing sustainability frontiers in the periurban. J South Asian Water Stud 6(1)

Marshall F, Dolley J (2019) Transformative innovation in peri-urban Asia. Res Policy 48(4):983-992

Marshall F, Randhawa P (2017) India's peri-urban frontier: rural-urban transformations and food security. IIED, London. https://pubs. iied.org/10794IIED. Accessed 15 Aug 2020

Marshall F et al (2018) Ecosystem services and poverty alleviation in urbanising context. In: Ecosystem services and poverty alleviation: Trade-offs and governance; Routledge London. https:// www.taylorfrancis.com/books/e/9780429016295. Accessed 15 Aug 2020

Martin M, Osella F (2019) Forecasting with fishers to save lives at sea SSRP (Sussex Sustainability Research Programme), University of Sussex and Institute of Development Studies, Brighton, UK. Policy Brief 2. https://www.sussex.ac.uk/ssrp/documents/ssrppolicy-brief-forecasting-for-fishers.pdf. Accessed 15 Aug 2020

*Menton M, Larrea C, Latorre S et al (2020) Environmental justice and the SDGs: from synergies to gaps and contradictions. Sustain Sci. https://doi.org/10.1007/s11625-020-00789-8

*Middleton J, Cassell JA, Colthart G et al (2020) Rationale, experience and ethical considerations underpinning integrated actions to further global goals for health and land biodiversity in Papua New Guinea. Sustain Sci. https://doi.org/10.1007/s11625-020-00805-x

Mngumi LE (2020) Ecosystem services potential for climate change resilience in peri-urban areas in Sub-Saharan Africa. Landscape Ecol Eng 16(2):187-198

Newell P, Taylor O, Touni C (2018) Governing food and agriculture in a warming world. Global Environ Pol 18:2. https://doi. org/10.1162/glep_a_00456

Newell P, Taylor O, Naess LO, Thompson J, Mahmoud H, Ndaki P, Rurangwa R, Teshome A (2019) Climate smart agriculture?
Governing the sustainable development goals in Sub-Saharan Africa. Front Sustain Food Syst 3(56)

*Nicholls E, Ely A, Birkin L et al (2020) The contribution of smallscale food production in urban areas to the sustainable development goals: a review and case study. Sustain Sci. https://doi. org/10.1007/s11625-020-00792-z

OECD (2019) Policy coherence for sustainable development 2019: empowering people and ensuring inclusiveness and equality. https ://doi.org/10.1787/a90f851f-en. Accessed 15 Aug 2020

OECD (2020a) A territorial approach to the Sustainable Development Goals: synthesis report. OECD Urban Policy Reviews, OECD Publishing, Paris. https://www.oecd-ilibrary.org/sites /0a305c62-en/index.html?itemId=/content/component/0a305 c62-en. Accessed 15 Aug 2020

OECD (2020b) Building back better: A sustainable, resilient recovery after COVID-19. OECD Policy Responses to Coronavirus. https://www.oecd.org/coronavirus/policy-responses/buildingback-better-a-sustainable-resilient-recovery-after-covid-1952b869f5/. Accessed 15 Aug 2020

Oliveira A, Calili R, Almeida MF, Sousa M (2019) A systemic and contextual framework to define a country's 2030 agenda from a foresight perspective. Sustainability 11(22):6360. https://doi. org/10.3390/su11226360

* Orchard S, Glover D, Thapa Karki S et al (2019) Exploring synergies and trade-offs among the sustainable development goals: collective action and adaptive capacity in marginal mountainous areas of India. Sustain Sci. https://doi.org/10.1007/s1162 5-019-00768-8

Rasmussen LV, Watkins C, Agrawal A (2017) Forest contributions to livelihoods in changing agriculture-forest landscapes. Forest Pol Econ 84:1-8

Ricciardi V et al (2018) How much of the world's food do smallholders produce? Global Food Secur 17:64-72

Rodrigues AS, Ewers RM, Parry L, Souza C, Veríssimo A, Balmford A (2009) Boom-and-bust development patterns across the Amazon deforestation frontier. Science 324(5933):1435-1437

Sachs J, Schmidt-Traub G, Mazzucato M, Messner M, Nakicenovic N, Rockström J (2019) Six transformations to achieve the sustainable development goals. Nat Sustain 2:805-814. https://doi. org/10.1038/s41893-019-0352-9

*Scharlemann JPW, Brock RC, Balfour N et al (2020) Towards understanding interactions between sustainable development goals: the role of environment-human linkages. Sustain Sci. https://doi. org/10.1007/s11625-020-00799-6

Scheidel A, Del Bene D, Liu J, Navas G, Mingorría S, Demaria F, Avila S, Roy B, Ertör I, Temper L, Martínez-Alier J (2020) Environmental conflicts and defenders: a global overview. Global Environ Change 63:102104

Thomas K, Hardy RD, Lazrus H et al (2019) Explaining differential vulnerability to climate change: a social science review. WIREs Clim Change. https://doi.org/10.1002/wcc.565

UN (2015) Transforming our world: The 2030 agenda for sustainable development. United Nations General Assembly (A/RES/70/1), New York

UN (2019) Annex: Gearing up for a decade of action and delivery for sustainable development: political declaration of the Sustainable Development Goals summit under the auspices of the United Nations General Assembly. Resolution 74.4, adopted by the General Assembly on 15 October 2019, New York. https://undocs.org/ en/A/RES/74/4. Accessed 15 Aug 2020

UN (2020a) Sustainable development goals partnership platform. https ://sustainabledevelopment.un.org/partnerships/. Accessed 15 Aug 2020

UN (2020b) Progress towards the sustainable development goals: Report of the Secretary General, 25 July 2019-22 July 2020. United Nations Economic and Social Council (E/2020/57). https:// 
unstats.un.org/sdgs/files/report/2020/secretary-general-sdg-repor t-2020--EN.pdf. Accessed 15 Aug 2020

UN DESA (2018). World urbanization prospects. The 2018 Revision, Highlights

UNDP (2004) Adaptation policy frameworks for climate change: developing strategies, policies and measures: Annex A. Glossary of terms; p. 249. https://www4.unfccc.int/sites/NAPC/Country\%20 Documents/General/apf\%20annexes $\% 20$ a\%20and\%20b.pdf. Accessed 15 Aug 2020

UNEP (2013) Drawing down $\mathrm{N}_{2} \mathrm{O}$ to protect climate and the ozone layer. A UNEP Synthesis Report. United Nations Environment Programme, Nairobi, Kenya. https://wedocs.unep.org/handl e/20.500.11822/8489. Accessed 15 Aug 2020

Weitz N, Carlsen H, Nilsson M, Skånberg K (2018) Towards systemic and contextual priority setting for implementing the 2030 Agenda. Sustain Sci 13:531-548. https://doi.org/10.1007/s1162 5-017-0470-0

Wilkinson E, Weingärtner L, Choularton R, Bailey M, Todd M, Kniveton D, Venton C (2018) Forecasting hazards, averting disasters: implementing forecast-based early action at scale. Overseas Development Institute, London

Yagi M, Kokubo K (2020) A framework of sustainable consumption and production from the production perspective: application to Thailand and Vietnam. J Clean Prod 276:124160
Zelasney J, Ford A, Westlund L, Ward A, Riego Peñarubia O (eds) (2020) Securing sustainable small-scale fisheries: showcasing applied practices in value chains, post-harvest operations and trade. FAO Fisheries and Aquaculture Technical Paper No. 652. FAO, Rome

Zhou X, Moinuddin M, Xu Z (2017) Sustainable development goals interlinkages and network analysis: a practical tool for SDG integration and policy coherence. Institute for Global Environmental Strategies, Kamiyamaguchi

Zhou X, Moinuddin M, Li Y (2019) SDG interlinkages analysis \& visualisation tool (V3.0). Institute for Global Environmental Strategies, Kamiyamaguchi. https://sdginterlinkages.iges.jp/visualisat iontool.html. Accessed 9 Oct 2020

Publisher's Note Springer Nature remains neutral with regard to jurisdictional claims in published maps and institutional affiliations. 